\section{Luxury bushmeat trade threatens lemur conservation}

SIR - Shocking new proof of an emerging trade in lemur bushmeat in Madagascar (see http://tinyurl. $\mathrm{com} / \mathrm{mqsx} 7 \mathrm{w}$ ) is refocusing attention on the conservation and health challenges in one of the world's most important biodiversity hotspots.

The growth of this market, in which lemurs are sold as a delicacy to luxury consumers, could mean extinction for alreadyendangered lemur species, which are found only in Madagascar. Furthermore, as in other countries, bushmeat hunting carries serious risks to public health by fostering emergence of disease.

Madagascar has experienced an upsurge in environmental crime since its political upheaval in March this year. Increasing illegal harvesting of precious hardwoods and animal trafficking bodes poorly for the future of Madagascar's already-degraded environment, where $90 \%$ of its original forest cover has been lost. Political chaos and the withdrawal of foreign aid mean that these environmental crimes have continued almost unchecked.

Russell Mittermeier, president of Conservation International, has warned that certain lemur species, such as the goldencrowned sifaka (Propithecus tattersalli), could vanish as a result of hunting for the new market. There may be as many as 99 lemur species in Madagascar (R. A. Mittermeier et al. Intl. J. Primatol. 29, 1607-1656; 2008). Wiping out any of these would disrupt the ecological balance and undermine the country's ecotourism industry.

Some $75 \%$ of emerging diseases have zoonotic origins (L. H. Taylor et al. Phil. Trans. R. Soc. Lond. B 356, 983-989; 2001). Ebola and simian foamy virus outbreaks, for example, as well as HIV, have been traced to bushmeat hunting and butchering. The increase in human-wildlife contact in
Madagascar's degraded forests, along with its extreme biodiversity and wide distribution of domestic animals, could enhance the risk of disease emergence and spread, potentially to a global level.

The country's interim government has responded to the crisis by firing several forestry officials, but more cohesive enforcement is needed. Mittermeier has urged the international community to reinstate conservation funding to Madagascar, in order to save this pinnacle of biodiversity. With $20 \%$ of the world's primate species in peril, and with increased risks of disease emergence, an integrated solution must and can be achieved by conservation, public health and development interests.

Meredith A. Barrett Box 90338, University Program in Ecology, Duke University, Durham,

North Carolina 27705, USA e-mail: meredith.barrett@duke.edu Jonah Ratsimbazafy Durrell Wildlife Conservation Trust, BP 8511, Antananarivo 101, Madagascar e-mail: jonah.ratsimbazafy@ durrell.org

\section{A communication wipeout by gabbling presenters}

SIR - I have noticed a trend among speakers at scientific conferences to speed up their oral presentations so that they can compress as much information as possible into their allocated time slots. Talking so fast can create a problem for those in the audience whose native language is not the one being used by the speaker - almost invariably English on today's stage.

For oral presentations to function as a clear mode of communication, I have some advice for speakers addressing an international audience. Bear in mind the diversity of your listeners and practise your talk on scientists whose first language is not English (and on those outside your discipline, in the case of a broader-themed conference); keep to the speed of a public-radio news broadcast; avoid cluttering your speech with unnecessary words and jargon; and do not launch into an unrelated story while presenting a text slide.

Contrary to popular belief, text slides and slide reading are not always boring, particularly for people listening to a talk in an unfamiliar language. And spare a thought for foreigners in the audience who may find jokes confusing: make sure that the humour translates!

Dongwook Ko School of Environmental and Life Sciences, Charles Darwin University, Darwin, Northern Territory 0909, Australia

e-mail:d.ko@uq.edu.au

\section{Politics and priorities behind Greek research reforms}

SIR - In your News story 'Greek scientists fight research shake-up' (Nature 460, 671; 2009), you indicate that research at the National Hellenic Research Foundation (NHRF) was judged to be generally poor during government-backed evaluations in 2001 and 2005. This is not the case.

On each occasion, three of the six NHRF institutes were toprated and named as centres of excellence. At none of the other three did the evaluators find the research weak.

Among those that were top-rated in 2005, the NHRF's Institute of Biological Research and Biotechnology (IBRB), of which I am director, was graded highest of the biological research institutes in the Attica region (including the Fleming institutes) and the second-highest in the country. Yet the IBRB is earmarked by the government for dissolution and absorption by the Alexander Fleming Biomedical Sciences Research Centre.

Concerning plans to restructure research in Greece, the scientific community is agreed that some changes are definitely required including more financial investment, greater respect for the process of scientific evaluation and the establishment of national priorities. However, the latest plans were not presented for discussion, so they are widely viewed as a policy that was chosen mainly to satisfy electoral prospects and client interests - with catastrophic consequences for the future of research in Greece.

The IBRB-NHRF is contributing to the national dialogue on the matter by presenting a detailed proposal for changes that could benefit the development of Greek biological research (see www.eie.gr).

Fragiskos N. Kolisis School of Chemical Engineering, National Technical University of Athens, and IBRB-NHRF, 48 Vassileos Constantinou Avenue, 11635 Athens, Greece e-mail: kolisis@eie.gr

\section{Overzealous use of decimal places has wrong kind of impact}

SIR - Scientists teach students to evaluate critically the significance of their measurements, and to eschew meaningless decimal places thrown up when pocket calculators work out a quotient of two integers. So what are we to make of the recently released impact factors, including Nature's much advertised rating of '31.434' (see also www.nature.com/ nature/about)? Has Thomson Reuters discovered a protocol that allows it to measure the impact of a journal with an accuracy of 32 p.p.m.?

Quoting this figure conveys the wrong impression - that innumerate marketing is trumping common sense at the heart of science's leading journal. J. M. D. Coey School of Physics and Centre for Research on Adaptive Nanostructures and Nanodevices, Trinity College, Dublin 2, Ireland e-mail: jcoey@tcd.ie. 